\title{
A Sensorless Vector Control Scheme for Induction Motors using a Space Phasor based Current Hysteresis Controller.
}

\author{
Ebenezer V. \\ Member IEEE \\ CEDT \\ ebenezer@india.ti.com
}

\author{
K. Gopakumar \\ Senior Member IEEE \\ CEDT \\ kgopa@cedt.iisc.ernet.in
}

\author{
V. T. Ranganathan \\ Senior Member IEEE \\ Electrical Eng. \\ vtran@ee.iisc.ernet.in
}

Phone- (80) 3341810, Fax- (80) 3341808

CEDT ( Centre for Electronics Design and Technology)

Indian Institute of Science

Bangalore, INDIA

Key words: space phasor based PWM, sensorless control

Abstract: The increasing use of AC machines compared to DC motors in electrical drive applications has several reasons. $A$ very important advantage of $A C$ machines is their simple construction. However, $A C$ drives often need mechanical sensors (tachometers, position encoders) for field orientation. In many applications these sensors reduce robustness and increase costs of a drive considerably. The objective of this paper is to present the practical implementation of a Sensorless Vector Control Scheme for Induction Motors using a Space Phasor based Current Hysteresis Controller. This scheme measures the stator current hysteresis error direction to determine the rotor flux position, during inverter zero vector states. This measurement of the rotor flux position is done indirectly by sensing the motor back emf, which is orthogonal to the rotor flux position. The basic idea is to measure the current hysteresis error direction of the stator current on the application of an inverter zero vector i.e. "short circuit at machine terminals". A generalization is possible by a combination of two (different) active states of the inverter. By a linear transformation of the electrical equations for both inverter states, a mathematical zero state is constructed. The use of this virtual short circuit is necessary at higher speeds when the inverter output voltage is fully utilized. However at low speeds the drop across the stator resistance is comparable to the motor back emf, to overcome this a simple paramether adaptation scheme is also presented here. The proposed scheme enables a smooth transition to six-step mode of operation.
The whole scheme is implemented using a Space Phasor based Current Hysteresis controller, in which the inverter voltage vectors close to the machine back emf vector is selected, without measuring the back emf vector. The back emf vector is sensed indirectly from the direction of the current error space phasor. A single chip solution is arrived at by using the TMS320F240 DSP from Texas Instruments.

\section{Introduction}

High dynamic performance drives such, as Field Oriented Control (FOC) schemes require complicated signal processing and costly encoders for computation of the rotor flux position.]. Sensorless control schemes using motor terminal voltages and currents, works very well at high speeds of operation, with the assumption that stator drops are negligible. However, the stator drops become significant at very low speeds of operation, demanding appropriate stator resistance compensation schemes for accurate rotor flux estimation.

Extending the speed range to very low speeds including standstill operation, by making use of the saliency effects in the rotor, calls for different rotor construction itself [1]. An accurate estimation of the rotor flux position and speed near standstill is proposed by J. Jiang and J. Holtz [2] by making use of the stator leakage inductance variation with change in rotor position.

In this paper, a simple rotor flux estimation scheme is proposed by measuring the current error space phasor direction of a space phasor based current hysteresis controlled PWM drive [4]. In the proposed scheme, the

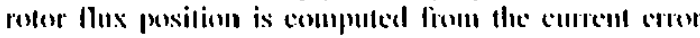
space phasor direction during zero inverter output states [3] . In this scheme the back emf computation is performed with the assumption that stator drops are negligible. But at very low speeds of operation stator drops are comparable to the back emf and rotor flux 
position estimation is no longer accurate. To overcome this an effective correction method is proposed. Thus, the speed range and the high dynamic performance can be extended to very low speeds of operation without any extra hardware. The rotor flux estimation scheme is presented in the following section.

\section{Machine Model}

Fig. I shows the steady state equivalent circuit model of the induction machine. The voltage equations in a stator-oriented reference frame is

$$
\underline{V_{k}}=\underline{i_{s}} R_{s}+L_{\sigma} \frac{d i_{s}}{d t}+\underline{V_{m}}
$$

where,

$$
\begin{aligned}
\frac{V_{k}}{V_{m}} & =\text { applied voltage vectors by inverter, } \\
\underline{L_{\sigma}} & =\text { stator leakage inductance, } \\
\underline{i_{s}} & =\text { stator current space phasor }
\end{aligned}
$$

Neglecting the stator resistance drop, equation(1) can be written as

$\underline{V_{k}}-\underline{V_{m}}=L_{\sigma} \frac{d \underline{\underline{s}}}{d t}$

where for a space phasor based current ${ }^{\text {h hysteresis }}$ controller, $\frac{d i_{s}}{d t}=\frac{\Delta I}{\Delta t}$,

and $\underline{\Delta} I=I_{\text {machine }}-\underline{I}$ reference, ( $\underline{I}$ reference is the reference current space phasor)

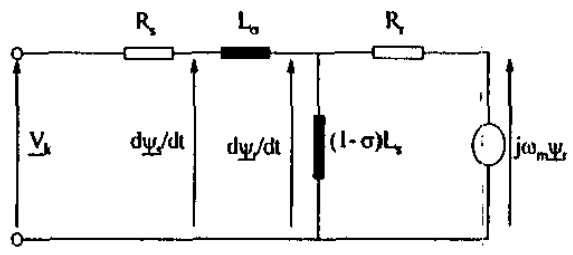

Fig.1 : Space Phasor based equivalent circuit of the induction machine

\section{Rotor Flux Detection using Inverter Zero} States

During inverter zero output states i.e. short circuit at the machine terminals the equation (2) can be rewritten as:

$$
\underline{V_{m}}=-L_{\sigma} \frac{d i_{s}}{d t}
$$

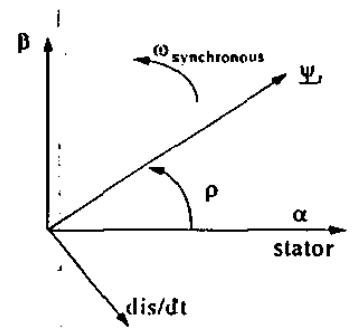

Fig.2 Relative position $\frac{d i_{s}}{d t}$ and
$\psi_{r}$ during zero inverter vector state

The flux is quadrature to the motor back emf and hence depending on the magnitude of the current errors along the real and imaginary axes, the rotor flux position can be estimated $(\cos \rho$ arid $\sin \rho$ ), during zero inverter output vector

\section{Rotor Flux Detection at higher speed ranges using arbitrary Inverter States}

At higher speed of operation, especially in the ficld weakening region no zero inverter output states occurs, and hence the rotor flux position is estimated by measuring the current error space plasors during two consecutive active inverter output vectors.

The following voltage equations are valid for two inverter states (the stator resistance is again neglected) within a short time period, in which the flux position does not change $\left(\rho_{1}=\rho_{2}\right)$ :

$$
\begin{aligned}
& \underline{V_{k 1}}=L_{\sigma} \frac{d i_{s l}}{d t}+\frac{d \psi_{r}}{d t} \\
& \underline{V_{k 2}}=L_{\sigma} \frac{d i_{s 2}}{d t}+\frac{d \psi_{r}}{d t}
\end{aligned}
$$

In equations (4) and (5) the rotor flux derivative is assumed to be the same during two consecutive non zero inverter output vector states and $\underline{V_{k 2}}={\underline{V_{k 1}}}^{ \pm j \frac{\pi}{3}}$. Thus from eqn.(10) and eqn.(11) the rotor flux position( $\rho$ ) can be computed, and is given as

$$
\begin{aligned}
& \rho=\arg \left(\frac{d i_{s 2}}{d t} e^{ \pm j_{3}^{\pi}}-\frac{d i_{s l}}{d t}\right)+ \\
& \frac{\pi}{2}\left(\operatorname{sign}\left(\omega_{\text {synchronons }}\right)\right)-\arg \left(1-e^{ \pm j \frac{\pi}{3}}\right)
\end{aligned}
$$


This is a very advantageous strategy for determining the flux angular position especially at higher speed and in the field-weakening range [3]. Note that no machine parameters influence the result of (6). Equation (6) is valid on the condition that the voltage drop on the stator resistance and the change of the rotor flux within the measurement period can be neglected. It is also assumed that the DC-link voltage is constant.

\section{Rotor Flux Detection at lower speed ranges} using simple parameter adaptation

At low speeds of operation the drop across the stator resistance is comparable to the motor back emf and the stator resistance drop which is significant at low speeds of operation has to be taken into account for the correct estimation of the rotor flux position. So eqn.(1) can be written, for zero inverter output vectors, at very low speed of operation as,

$$
\frac{V_{m}}{\overline{R_{s}}}=-\left(\underline{i_{s}}+\frac{L_{\sigma}}{R_{s}} \frac{d \underline{i_{s}}}{d t}\right)
$$

Now during zero inverter output period the currents are sampled at two instants $\left(\tau_{1}\right.$ and $\left.r_{2}\right)$ and from this the eqn.(7) can be written as ( using backward differentiation)

$\underline{V_{m}} / R_{s}=-i_{\underline{k}}-\frac{L_{\sigma}}{R_{s}}\left(\left(i_{\underline{k}}-i_{\underline{k-1}}\right) / \tau_{l}\right)$

${\underline{V_{m}}}^{\prime} / R_{s}=-i_{\underline{k}+1}-\frac{L_{\sigma}}{R_{s}}\left(\left(\underline{i}_{\underline{k}+1}-i_{\underline{k}}\right) / \tau_{2}\right)$

Assuming that the $V_{m}$ does not change, during $\left(\tau_{1}\right.$ and $\left.\tau_{2}\right)$, from eqn.(8)and(9)

$$
\begin{aligned}
& \frac{L_{\sigma}}{R_{s}}=\left\{\left(i_{\underline{k}}-i_{\underline{k+1}}\right) \tau_{1} \tau_{2}\right\} / \\
& \left\{\tau_{l}\left(\underline{i}_{\underline{k+1}}-i_{\underline{k}}\right)-\tau_{2}\left(i_{\underline{k}}-i_{\underline{k-1}}\right)\right\}
\end{aligned}
$$

Eqn.(10) is computed during zero interval period and substituted in eqn.(7)to find the rotor flux position. Since the machine parameters do not change very rapidly, the value $\mathrm{L}_{\sigma} / \mathrm{Rs}$ can be averaged out over a time range say over $2 \mathrm{~min}$. and can be updated in that time step. To begin with one can start with the cold parameter values of the machine given and update it subsequently after the first averaging is made.

\section{Space Phasor based Current Hysteresis Controller}

In conventional three phase current hysteresis controllers, the current error along the three phase axes are independently controlled. This will result in random selection of switching vectors causing high inverter switching losses. In this scheme, a space phasor based multi axis current hysteresis controller is proposed, in which the current error along the orthogonal axes $(\mathrm{jA}, \mathrm{jB}, \mathrm{jC})$ are monitored[4].The current error boundary (Fig. 3 ) is a hexagon and the current error is controlled in such a way that, only the three adjacent voltage vectors in a sector are always used for the entire speed range [4]. The scheme can be implemented using simple look up tables (Table-1). The advantages of the scheme, when compared to other multi level current hysteresis controllers, is that only the adjacent vectors close to the motor back emf space phasor voltage, are used for the inverter switching, for the entire speed range (optimum PWM switching). In the present scheme, the selection of the inverter voltage vectors for optimum PWM switching is achieved

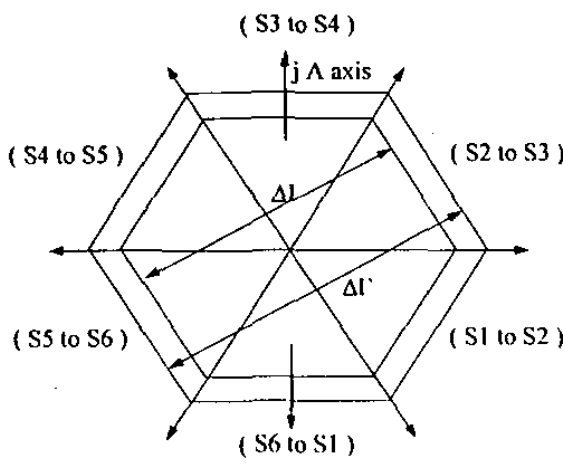

Fig.3 Current error space phasor boundary

without any computation of the machine voltage space phasor, for the full speed range of the drive system. The scheme is self adapting, as far as the motor space phasor voltage is concerned, and also maintains the controller simplicity and quick response features of a hysteresis current controller[4]. In Figure(3) the current hysteresis boundary is shown, for the proposed scheme. In choosing the inverter states, for switching in various sectors, it is taken care of that (a) only, adjacent vectors, close to the machine voltage space phasor $\left(V_{m}\right)$, are always chosen for current control, (b) among the adjacent vectors, the vector which gives the maximum current error change in the opposite direction, is chosen for the next switching. Taking all this into account, the vector states, which gives optimum PWM vector selection, in a sector are chosen, as shown in Table-1. The outer hysteresis boundary $\left(\Delta I^{\prime}\right)$ is for the sector selection in which the motor back emf is situated. For an inverter output vector, there is a definite current error spacer direction, along which the current error space phasor approaches the hexagonal boundary (Fig.3)[4]. This is detected for the vector forming a triangular sector in which the back emf vector is situated. 


\begin{tabular}{|c|c|c|c|c|c|c|c|c|c|c|c|c|c|}
\hline $\mathrm{Y}$ & $-9 \mathrm{jC}$ & $\begin{array}{c}-8(-\mathrm{jC} C \\
+\mathrm{j} \Lambda)\end{array}$ & $\begin{array}{c}-6(\mathrm{jB} \\
-\mathrm{j} \mathrm{C})\end{array}$ & $-3 \mathrm{jB}$ & $\begin{array}{c}-2(\mathrm{jA}- \\
\mathrm{j}(3)\end{array}$ & $-1(\mathrm{jA})$ & 0 & $1(\mathrm{jA})$ & $\begin{array}{c}2(-\mathrm{j} \Lambda \\
+\mathrm{j}(3)\end{array}$ & $3(\mathrm{jB})$ & $\begin{array}{c}6(-\mathrm{jB} \\
+\mathrm{j} C)\end{array}$ & $\begin{array}{c}8(\mathrm{jC}- \\
\mathrm{j} \Lambda)\end{array}$ & $9(\mathrm{jC})$ \\
\hline $\mathrm{S} 1$ & 1 & $\mathrm{I}$ & 1 & $\mathrm{Z}$ & $\mathrm{Z}$ & 2 & 0 & $\mathrm{Z}$ & 2 & 1 & $\mathrm{Z}$ & 2 & 2 \\
\hline $\mathrm{S} 2$ & $\mathrm{Z}$ & $\mathrm{Z}$ & 2 & 3 & $\mathrm{Z}$ & 2 & 0 & $\mathrm{Z}$ & 2 & 2 & 3 & 3 & 3 \\
\hline $\mathrm{S} 3$ & $\mathrm{Z}$ & $\mathrm{Z}$ & $\mathrm{Z}$ & 4 & 4 & 3 & 0 & 4 & 3 & $Z$ & 4 & 3 & 3 \\
\hline $\mathrm{S} 4$ & 5 & 5 & $\mathrm{Z}$ & 4 & 5 & $\mathrm{Z}$ & 0 & 5 & $\mathrm{Z}$ & $\mathrm{Z}$ & 4 & 4 & 4 \\
\hline $\mathrm{S} 5$ & 6 & 6 & 6 & 5 & 5 & $\mathrm{Z}$ & 0 & 5 & $\mathrm{Z}$ & 6 & 5 & $\mathrm{Z}$ & $\mathrm{Z}$ \\
\hline $\mathrm{S} 6$ & 6 & 6 & 1 & $\mathrm{Z}$ & 6 & 1 & 0 & 6 & 1 & 1 & $\mathrm{Z}$ & $\mathrm{Z}$ & $\mathrm{Z}$ \\
\hline
\end{tabular}

TABLE-1. Vector switching look up table for the multi axis space phasor based current hysteresis controller.

1 to 6 are inverter switching vectors, $Z$ - zero vector, 0 - continue with the previous state

When the back emf vector moves to the next sector, and if the inverter switching vectors are not chosen from the same sector, the current error moves out of the inner hexagonal boundary, and this is detected by the outer hysteresis boundary, and the appropriate sector is selected [4].

\section{Experimental results}

The proposed scheme is implemented with a fixed point digital signal processor (DSP), the TMS320F240. A vector controller scheme is implemented using the proposed rotor flux position estimation scheme, for a $10 \mathrm{HP}$ induction motor. The Rotor flux position signal $(\cos \rho$ and $\sin \rho)$ for three different speed
Fig. 2 shows the motor phase voltage wave form obtained from space phasor based current hysteresis controller for two different speed ranges. Fig.2b shows the PWM voltage waveform near $50 \mathrm{~Hz}$ operation. As the speed increases the zero inverter vector period slowly decreases and the inverter switching vectrors are chosen from the active vectors, forming a sector, in which the machine back emf is located. As the speed becomes close to $50 \mathrm{~Hz}$, the inverter switchings will slowly come to the six-step operation( Fig.2b). Fig.3 shows current wave form during acceleration. The motor speed signal, derived from the proposed sensorless control scheme and the computed rotor flux position signal $(\cos \rho)$ are shown in Fig.(4), duritig a speed reversal operation. The proposed sensorless
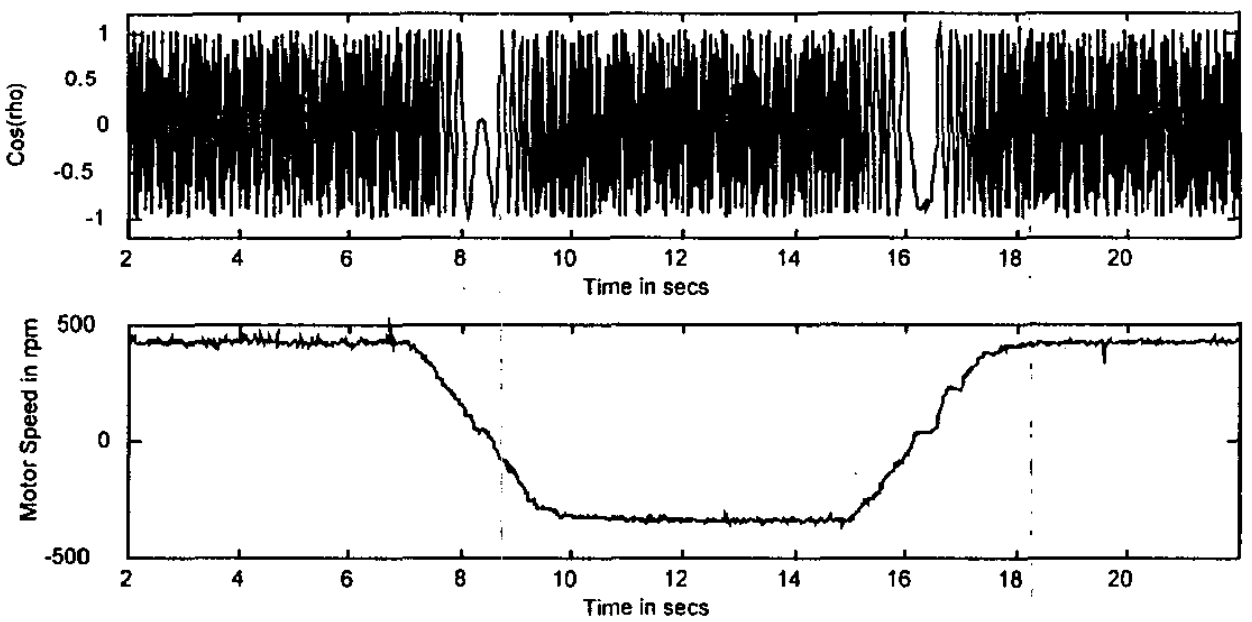

Fig.4 Flux position signal and the motor specd signal during speed transicnts

ranges, obtained from the proposed experimental setup, are shown in Fig.la, Fig.lb, and Fig.lc. The motor speed is derived from the computed position signals( $\cos \rho$ and $\sin \rho)$ as explained in appendix-A. speed control system worked satisfactorly down to a $3 \mathrm{~Hz}$ frequency of operation, with smooth speed reversals. 


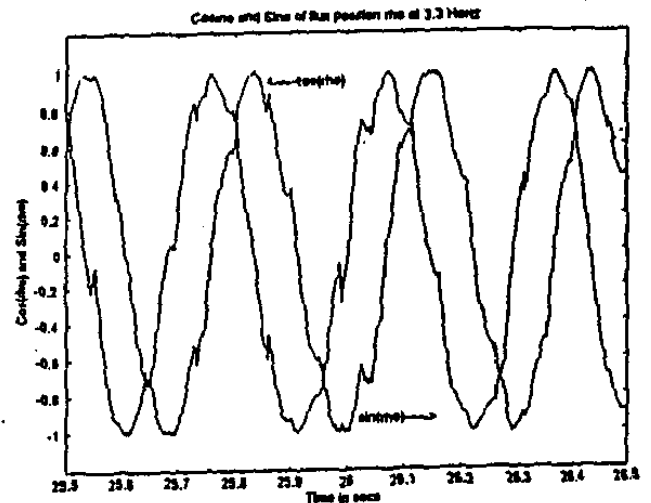

Fig.1a : Flux position signals at $3.3 \mathrm{~Hz}$

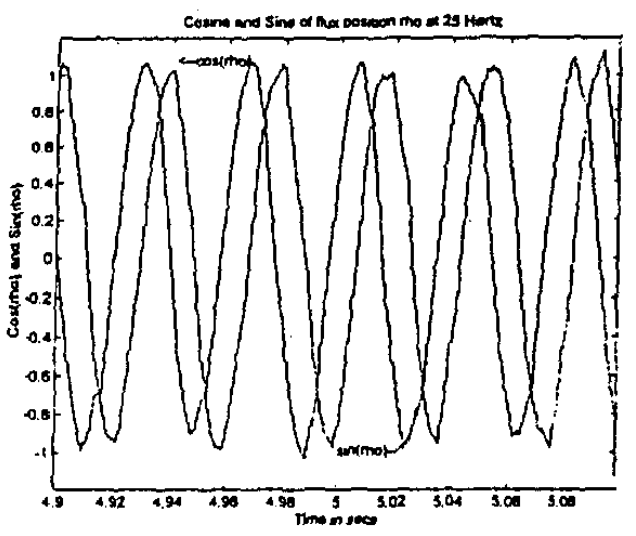

Fig.1c: Flux position signals at $25 \mathrm{~Hz}$

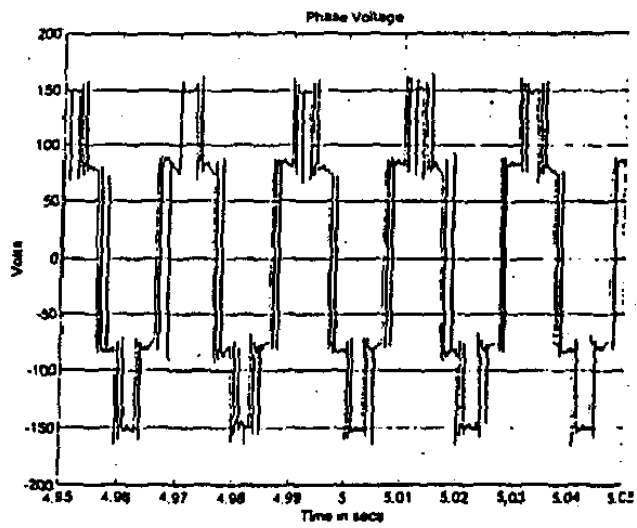

Fig. 2b: Motor phase voltage- near $50 \mathrm{~Hz}$ range

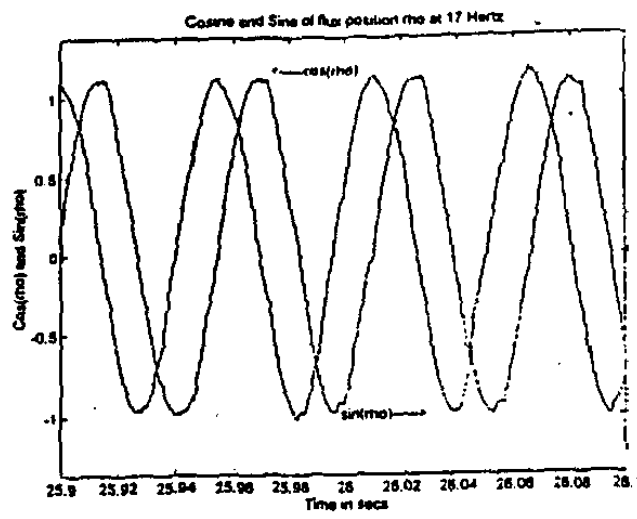

Fig. 1b: Flux position signals at $17 \mathrm{Bz}$

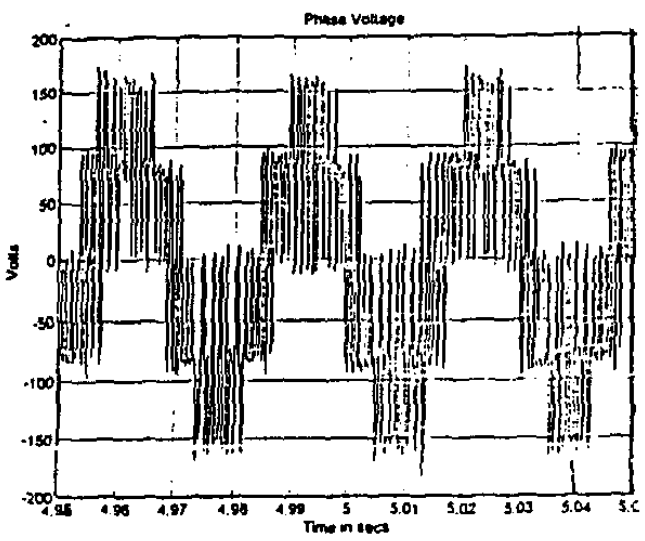

Fig.2a: Motor phase voltage- Low speed range

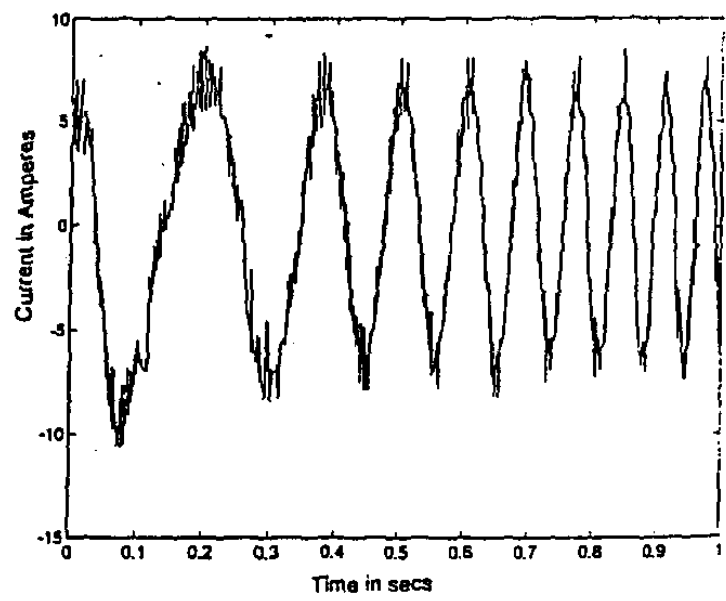

Fig. 3: Motor phase current during acceleration 


\section{References}

[1] Jansen, P.L., Lorenz, R.D: "Transducerless position and velocity Estimation in induction and salient AC machines", IEEE Trans. Ind.appl., Vol.31, No.2, pp.240-247, 1995.

[2] Jinsheng Jiang and Joachim Holtz:" An accurate Estimator of Rotor position and speed of induction motor near stand still", Int. Conf. IEEE, PEDS-97, pp. 1-5, Singapore - 1997.

[3] Schroedl, M., Wieser, R.S.: " E.M.F. - based Rotor Flux Detection in Induction Motors Using Virtual Short Circuits", IEEE Conf. IAS-96, pp. 229-233.

[4] Mistry,V., Waikar, S.P., Umanand, L., Gopakumar, K., Ranganathan, V.T.: "A Multi Axis Space Phasor Based Current Hysteresis Controller For PWM Inverters", Int. Conf. IEEE, PEDS-97, pp. 480-486, Singapore - 1997.

\section{APPENDIX-A}

\section{Speed Signal Computation}

The computed cos $\rho$ and sin $\rho$ signals are passed through a low pass filter. The transfer function of the low pass filter is

$\mathrm{G}(\mathrm{s})=\frac{1}{1+j \omega T}=\frac{1}{\sqrt{1+\omega^{2} T^{2}}}-\tan ^{-1} \omega T$

$=\mathrm{X}+\mathrm{j} \mathrm{Y}$, where, $\mathrm{X}=\frac{1}{1+\omega^{2} T^{2}}$ and

$$
\mathrm{Y}=\frac{-\omega T}{1+\omega^{2} T^{2}}
$$

\section{Sinusoidal input to the filter}

When the sinusoidal input $(\sin \rho)$ with unit amplitude is passed through the filter, the polar plot of the signal from the filter output traces a semicircle as shown in Fig.1A.

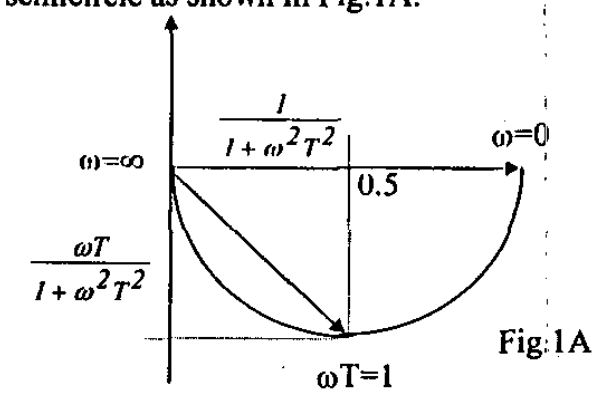

2.For a COSINE input of same amplitude and frequency, the polar plot of the filter output is also a semi circle with a $90^{\circ}$ phase lead ( Fig.2A)

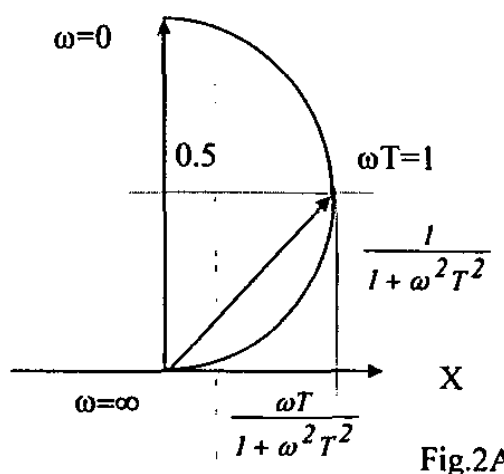

When the $\cos \rho$ and sin $\rho$ signals are passed through the filter, the filtered out put signals have the same amplitudes and same phase shifts with respect to the input signals. ie.,

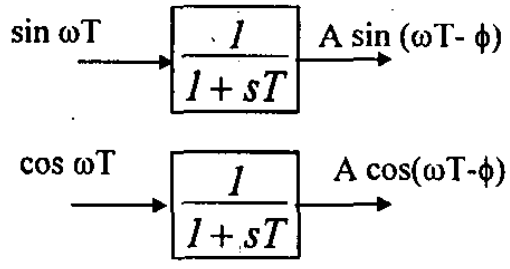

Now from Fig.1A ,Fig.2A and using the identities

$$
\begin{aligned}
& {[\operatorname{Sin} \omega \mathrm{T} A \operatorname{Sin}(\omega \mathrm{T}-\phi)+} \\
& \operatorname{Cos} \omega \mathrm{T} A \operatorname{Cos}(\omega \mathrm{T}-\phi)]=A \cos \phi=\frac{1}{1+\omega^{2} T^{2}}
\end{aligned}
$$

$[\operatorname{Sin} \omega \mathrm{T} A \operatorname{Cos}(\omega \mathrm{T}-\phi)-$

$$
\operatorname{Cos} \omega \mathrm{T} A \operatorname{Sin}(\omega \mathrm{T}-\phi)]=A \sin \phi=\frac{-\omega T}{1+\omega^{2} T^{2}}
$$

Now eqn. $4(\mathrm{~A}) \div$ eqn. $3(\mathrm{~A})$ is ' $-\omega \mathrm{T}$ ', where $\mathrm{T}$ is the filter time constant. Thus the speed signal can be derived using simple first order filter circuit. 